\title{
Vzorci zasedbe prostora za potrebe sprostitve in rekreacije $v$ obmestnem prostoru: primer Jezero pri Podpeči, Slovenija
}

Članek obravnava vprašanja o nosilni sposobnosti prostora za sprostitev in rekreacijo $\mathrm{v}$ obmestnih krajinah visokih naravnih ali kulturnih vrednot. Temelji na konceptu pristopov od spodaj navzgor, pri čemer uporablja metodo opazovanja in vedenjskih zemljevidov, ki temelji na drobnih kvalitativnih podatkih. Osredotoča se na zasnovo koncepta nosilne sposobnosti naravno vrednega območja za rabo in na ugotavljanje ocene nosilne sposobnosti takega območja za rabo. Izhajali smo iz Goličnik Marušić (2015), ki nakazuje smisel obravnave razvoja in načrtovanja zelene infrastrukture $\mathrm{z}$ vidika uporabnikovih potreb in navad ter s konceptom nosilne sposobnos- ti prostora za zasedbo vključili tudi varstveni vidik. $\mathrm{Na}$ podlagi izvedenih podatkov, pridobljenih z opazovanjem in kartiranjem vedenja, smo komentirali dejansko rabo, uporabnike $\mathrm{z}$ vidika starostnih skupin ter način zasedanja prostora, pogostost pojavljanja dejavnosti in načine zadrževanja v prostoru na primeru Jezera pri Podpeči, priljubljene izletniško-rekreacijske točke na robu Ljubljanskega barja.

Ključne besede: nosilna sposobnost, zelena infrastruktura, vedenjski zemljevid, periurbane krajine, prostorsko načrtovanje 


\section{Uvod}

Prispevek se osredotoča na proučevanje uporabe obmestnih krajin za potrebe rekreacije ter na razvoj in testno preverjanje koncepta nosilne sposobnosti prostora za rekreacijo in sprostitev. Temelji na komentarjih opazovanj in vedenjskih zemljevidov vzorcev uporab prostora, pri čemer so bila opazovanja pilotno izvedena v okviru projekta LOS_DAMA! - Landscape and Open Space Development in Alpine Metropolitan Areas, ki je bil odobren na drugem razpisu programa mednarodnega teritorialnega sodelovanja Območje Alp 2014-2020. Projekt se ukvarja $s$ krajino v zaledju mestnih območij kot delom širših omrežij zelene infrastrukture, ki je privlačna zaradi naravnih in kulturnih virov ter dediščine. Zaradi tega je s svojo pestrostjo in lego pogosto izpostavljena pritiskom za različne rabe. $\mathrm{Na}$ podlagi opazovanj dveh izbranih območij Ljubljanskega barja, tipične zaledne krajine ljubljanske urbane aglomeracije, smo predstavili nekatera razmišljanja o možnih spremljanjih pritiskov na prostor zaradi potrebe po sprostitvi in rekreaciji ter opredelili koncept nosilne sposobnosti območja za rabo. Opazovanja in kartiranja vedenj so bila pilotno izvedena za Jezero pri Podpeči, priljubljeno in pogosto obiskano destinacijo na Ljubljanskem barju. Jezero pri Podpeči je kot brezno s stalnim ponorom zavarovano kot geomorfološka naravna vrednota državnega pomena, njegovo širše območje je zavarovano tudi kot hidrološka in ekosistemska naravna vrednota državnega pomena in je hkrati naravni spomenik. Širše območje jezera spada v tretje varstveno območje krajinskega parka Ljubljansko barje (ARSO, 2019).

Zelena infrastruktura kot interpretacija trajnostnega koncepta prostorskega načrtovanja in prilagajanja podnebnim spremembam omogoča različne priložnosti za blaženje škodljivih učinkov, ob hkratnem zagotavljanju okoljskih, gospodarskih in socialnih koristi, vključno $s$ kakovostjo bivanja in zdravjem ljudi. Koncept zelene infrastrukture se je v zadnjih desetletjih uveljavil v glavnem kot protiutež sivi infrastrukturi (grajeno okolje). Njegova vloga se je najprej in najmočneje izrazila na področju blaženja podnebnih sprememb v mestih (npr. Gill idr., 2007). Z vsebinsko-tehnoloških vidikov se je tako kot $\mathrm{v}$ prostorskem načrtovanju nasploh pri evidencah elementov zelene infrastrukture uveljavil pristop na podlagi GIS, s poudarkom na interpretaciji podatkov namenske rabe in morfoloških značilnosti (npr. Chang idr., 2011). V zadnjem času se po številnih študijah, ki dokazujejo pozitivno korelacijo med zelenimi odprtimi prostori v mestih in človekovim zdravjem (npr. Ward Thompson, 2013), ta vloga prenaša tudi na vlogo zelene infrastrukture. Po čedalje večjem uveljavljanju koncepta ekosistemskih storitev je boljše tudi razumevanje zelene infrastrukture kot nosilke posameznih vidikov ekosistemskih storitev (oskrbovalne, uravnalne, kulturne, podporne), kar zahteva tudi večdisciplinarni pristop $\mathrm{k}$ obravnavi zelene infrastrukture (npr. Tzoulas idr., 2007; Taylor in Hochuli, 2017) in oceno večnamenske vloge zelene infrastrukture za največje možno zagotavljanje ekosistemskih storitev (Meerow in Newe11, 2016).

Pri čedalje več utemeljevanjih konceptov pomena biotske raznovrstnosti, varstva okolja in načrtovanja prostora v obliki koncepta zelene infrastrukture (npr. Evropska komisija, 2013; Evropska komisija, 2016), ekosistemskih storitev (npr. Evropska komisija, 2018) in na naravi temelječih rešitev (npr. Raymond idr., 2017) je z vidika urejanja prostora ključno vzpostaviti nove mehanizme in na elemente prostora pogledati ne le $\mathrm{z}$ vidika njihove fizične pojavnosti in klasifikacije $\mathrm{v}$ sivo, modro ali zeleno infrastrukturo, temveč prostor razumeti kot sistem procesov narave in človeka (Goličnik Marušić in Praper Gulič, 2018). Podobno utemeljujeta tudi Parker in Zegoni de Baro (2019) z zavzemanjem za to, da bi se koncept zelene infrastrukture razširil in obsegal širše vidike, ki so lahko povezani z zeleno infrastrukturo. Tudi v tem članku zeleno infrastrukturo obravnavamo s širšega vidika, tj. $z$ vidika njene privlačnosti za rekreacijsko rabo. Izbranih elementov zelene infrastrukture ne osvetlimo neposredno z njihovimi morfološkimi, strukturnimi ali ekološkimi lastnostmi, temveč se osredotočamo na interpretacijo teh prostorov z vidika rekreativnih dejavnosti, ki jih ti prostori spodbujajo. Tak pristop $\mathrm{k}$ obravnavi zelene infrastrukture je nov in se neposredno navezuje na začrtano hipotezo: Vrsta, pogostost, intenzivnost in dimenzije uporab prostora lahko opredelijo nosilnost prostora in s tem izražajo razsežnosti zasedbe prostora za rekreacijo, ki jo prostor/narava lahko prenese.

\subsection{Metodologija in zajem podatkov}

V skladu z metodo opazovanje in vedenjski zemljevidi (npr. Goličnik in Ward Thompson, 2002; Goličnik, 2006) sta bila predhodno izdelana urnik in protokol opazovanj, izbran je bil način zapisa opazovanj ter pripravljeni so bili simboli in kartografske osnove za zapis opazovanj. Opazovanje in evidentiranje vedenj sta bila izvedena od 9. 6. do 3. 7. 2018, ki zajema čas konca šolskega leta in začetka počitnic, ter na dodatni opazovalni dan 19. 8. 2018, ob izteku šolskih počitnic. Celoten dan je bil razdeljen na nize dopoldanskih in popoldanskih opazovanj. Dopoldanska opazovanja so bila izvedena med 10.00 in 13.00 , popoldanska pa med 14.00 in 19.00 . Posamezno opazovanje območja, ki ga je mogoče proučevati s pogledom in pri tem oceniti starost, spol in dejavnost uporabnika, je na Jezeru pri Podpeči, kjer je mogoče celotno območje uporabe zaradi strukturno-morfoloških lastnosti območja opazovati naenkrat, trajalo 30 minut. Glede na opazovalne intervale je bilo opravljenih 28 opazovanj. Popoldanska opazovanja so pogosto prekinile ali onemogočile poletne nevihte. Opazovanja 
Tabela 1: Kodirni sistem za vnos ročno zbranih podatkov v program ArcGIS

\begin{tabular}{|c|c|c|c|c|}
\hline \multicolumn{3}{|c|}{ Točkovni vnosi } & \multicolumn{2}{|c|}{ Poligonski vnosi } \\
\hline Spremenljivka & Šifra & Opis/razred & Šifra & Opis/razred \\
\hline \multirow{12}{*}{ Dejavnost } & 1 & čolnariti & 1 & čolnariti \\
\hline & 2 & hoditi & 2 & hoditi \\
\hline & 3 & hoditi s psom & & \\
\hline & 4 & igrati se & 4 & igrati se \\
\hline & 5 & kolesariti & & \\
\hline & 6 & ležati & 6 & ležati \\
\hline & 7 & plavati & 7 & plavati \\
\hline & 8 & loviti ribe & 8 & loviti ribe \\
\hline & 9 & sedeti & 9 & sedeti \\
\hline & 10 & sedeti s psom & & \\
\hline & 11 & stati & 11 & stati \\
\hline & & & 12 & imeti piknik \\
\hline \multirow{7}{*}{ Starost } & 1 & $\leq 5$ let - otrok/družina & 4 & družina \\
\hline & 2 & $6-12$ let - otrok/družina & 4 & družina \\
\hline & 3 & $13-19$ let - najstnik & 1 & najstnik \\
\hline & 4 & 20 -34 let - mlajši odrasel & 2 & mlajši odrasel \\
\hline & 5 & $35-50$ let - mlajši odrasel & 2 & mlajši odrasel \\
\hline & 6 & $51-65$ let - starejši odrasel & 3 & starejši odrasel \\
\hline & 7 & $>65$ let - starejši odrasel & 3 & starejši odrasel \\
\hline \multirow{4}{*}{ Spol } & 1 & moški & 1 & skupina moških \\
\hline & 2 & ženska & 2 & skupina žensk \\
\hline & & & 3 & mešana skupina \\
\hline & & & 4 & družina \\
\hline \multirow{4}{*}{ Velikost skupine } & & & 3 & 3 ljudje \\
\hline & & & 4 & 4 ljudje \\
\hline & & & 5 & 5-10 ljudi \\
\hline & & & 6 & 10 ljudi in več \\
\hline \multirow{6}{*}{ Del dneva } & 1 & $10.00-12.00$ & 1 & $10.00-12.00$ \\
\hline & 2 & $12.00-14.00$ & 2 & $12.00-14.00$ \\
\hline & 3 & $10.00-14.00$ & 3 & $10.00-14.00$ \\
\hline & 4 & $14.00-17.00$ & 4 & $14.00-17.00$ \\
\hline & 5 & $17.00-19.00$ & 5 & $17.00-19.00$ \\
\hline & 6 & $14.00-19.00$ & 6 & $14.00-19.00$ \\
\hline \multirow{2}{*}{ Del tedna } & 1 & pon. -pet. & 1 & pon. -pet. \\
\hline & 2 & sob. -ned. /praznik & 2 & sob. -ned. /praznik \\
\hline \multirow{4}{*}{ Vreme } & 1 & sončno & 1 & sončno \\
\hline & 2 & delno oblačno & 2 & delno oblačno \\
\hline & 3 & oblačno & 3 & oblačno \\
\hline & 4 & deževno & 4 & deževno \\
\hline \multirow{5}{*}{ Temperatura } & 1 & $15-19^{\circ} \mathrm{C}$ & 1 & $15-19^{\circ} \mathrm{C}$ \\
\hline & 2 & $20-24^{\circ} \mathrm{C}$ & 2 & $20-24^{\circ} \mathrm{C}$ \\
\hline & 3 & $25-29^{\circ} \mathrm{C}$ & 3 & $25-29^{\circ} \mathrm{C}$ \\
\hline & 4 & $30-34^{\circ} \mathrm{C}$ & 4 & $30-34^{\circ} \mathrm{C}$ \\
\hline & 5 & $\geq 35^{\circ} \mathrm{C}$ & 5 & $\geq 35^{\circ} \mathrm{C}$ \\
\hline
\end{tabular}



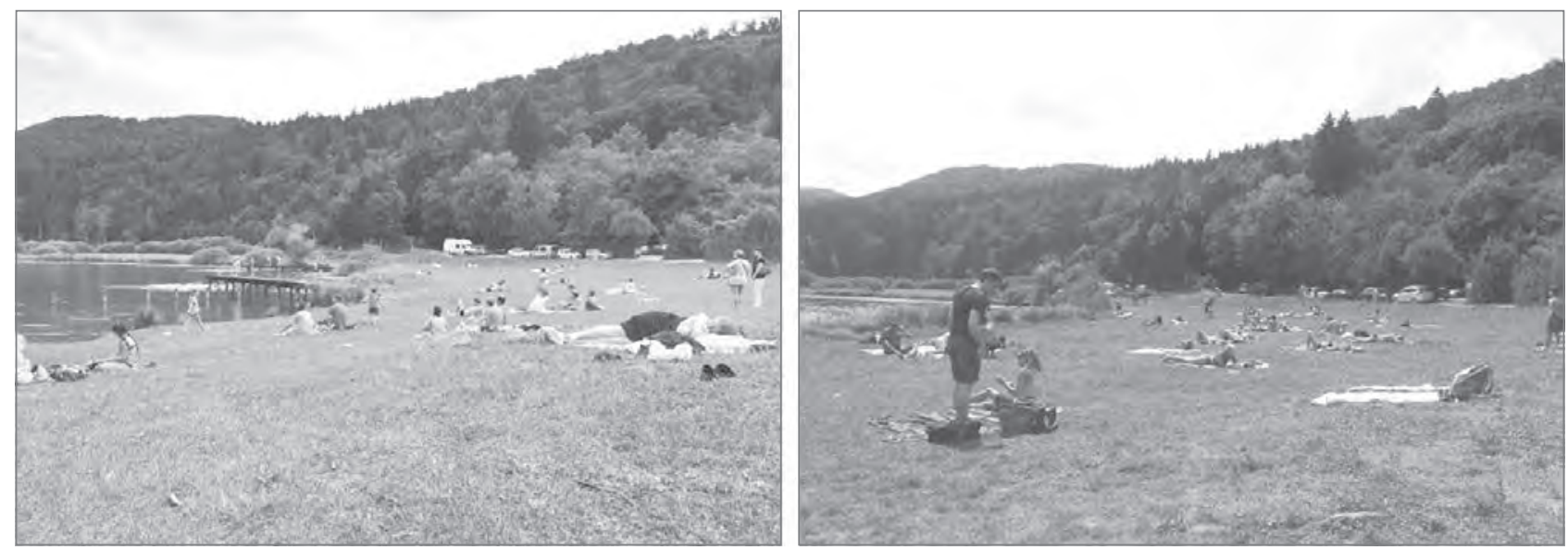

Slika 1: Velik obisk: Število obiskovalcev jezera, 17. 6. 2018, in obiskanost sredi dneva 19. 8. 2018 (foto: Manca Dremel)
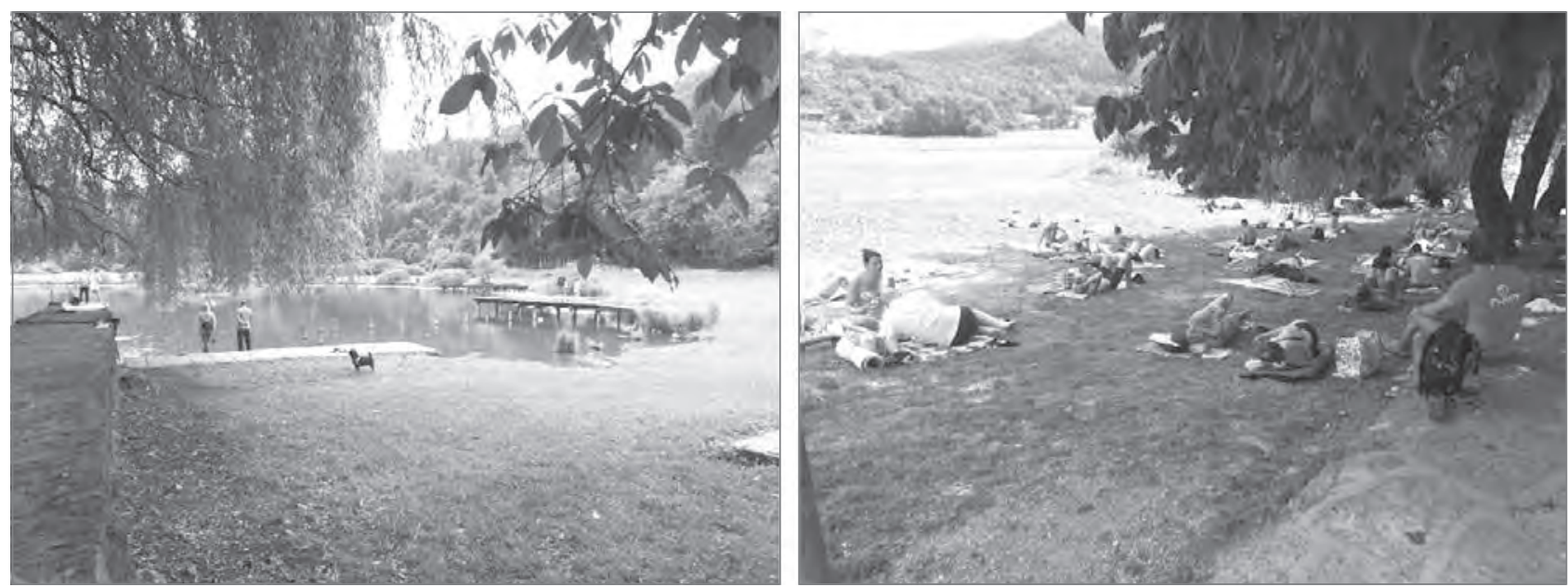

Slika 2: Nasprotje med velikim in majhnim obiskom: Obisk ob slabšem vremenu 29. 6. 2018 in iskanje sence 19. 8. 2018 (foto: Manca Dremel)

so bila predvidena med tednom in ob koncu tedna, a so začetna opazovanja pokazala, da je z vidika intenzitete obiska ključno pridobiti podatke ob koncu tedna. Končno razmerje opazovalnih dni je bilo: štirje dnevi ob koncu tedna in šest dni med tednom. V nadaljevanju so podrobneje predstavljeni izsledki opazovanj, rezultati so komentirani za dneve, ko je bil obisk velik.

Podatki opazovanj so bili zajeti ročno, in sicer tako, da so bili posamezniki ali pari evidentirani kot točkovni simboli, ki so izražali vrsto dejavnosti in spol uporabnika. Dodatno so bili opremljeni s šiframi za starostno skupino, ki ji posameznik pripada, in za čas zadrževanja ali trajanje dejavnosti na prostoru. Kadar so bili v dejavnost vključeni trije ali več posameznikov, so bila kartirana območja skupin, pri čemer so bile ob območju podane oznake za vrsto dejavnosti ter šifre za sestavo skupine glede na starost in spol ter velikostni red skupine (število posameznikov v skupini). Poleg osnovnih zapisov o tem, kaj obiskovalci počnejo, kje, kako dolgo, koliko so stari in ali so moški ali ženske, so bili za vse spremenljivke (posamezniki in skupine) zbrani še podatki, ki pojasnjujejo druge okoliščine: del dneva, del tedna in osnovni podatki o vremenu. Kartografska osnova za zaris vedenjskih zemljevidov je bilo kartografsko gradivo odprtokodnega dostopa OpenStreetMap. Digitalni zapis ročno zbranih podatkov je nastal $\mathrm{z}$ računalniškim programom ArcGIS (Esri). Posamezniki so bili vneseni kot spremenljivke tipa točka in skupine kot spremenljivke tipa poligon. Vsakemu vnosu je bila pripisana zaporedna identifikacijska številka in vsak vnos je bil opremljen po naslednjem kodirnem sistemu.

\section{Analiza}

Dejanska raba prostora za rekreacijo in sprostitev je bila analizirana in komentirana glede na niz parametrov, ki lahko značilno opredeljujejo ali zaznamujejo zasedbo prostora. Osnovne opisne analize izhajajo iz neposredno zbranih podatkov in uporabo prostora komentirajo glede na število obiskovalcev, vrsto druženja (posamično ali v paru, skupine), čas obiska (dopoldne ali popoldne, konec tedna ali med tednom) in starostno strukturo obiskovalcev (otroci, mladostniki, mlajši odrasli, starejši odrasli, starostniki). Za pripravo koncepta nosilne spo- 


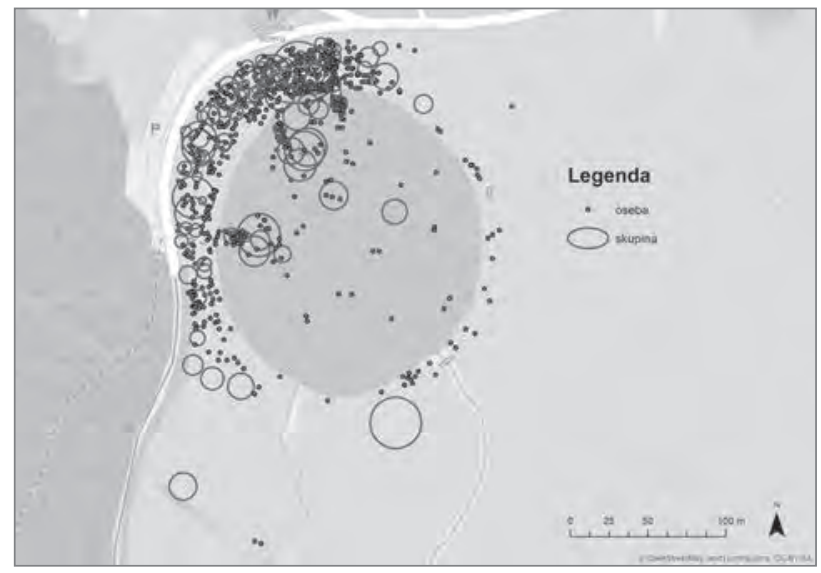

Slika 3: Kumulativni vedenjski zemljevid za Jezero pri Podpeči, junij avgust 2018 (izdelala: Nevenka Mihevc, vir: OpenStreetMap, terenski zajem podatkov)

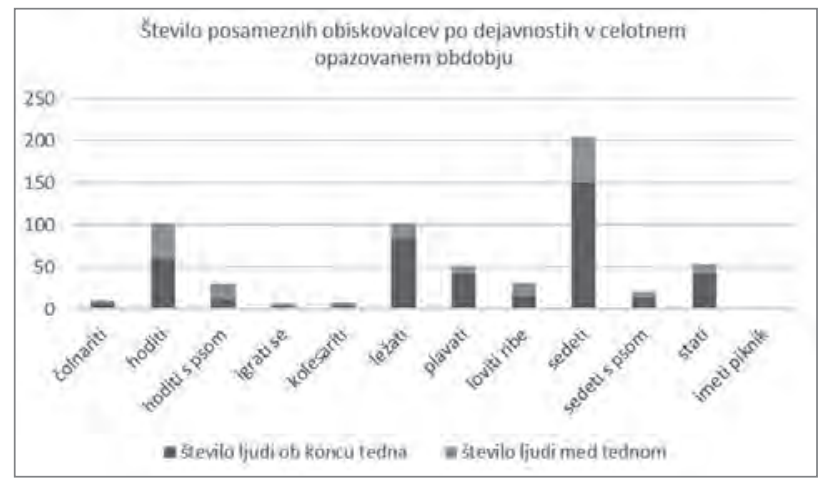

Slika 4: Število posameznih obiskovalcev po dejavnostih v celotnem opazovanem obdobju (izdelala: Barbara Goličnik Marušić)

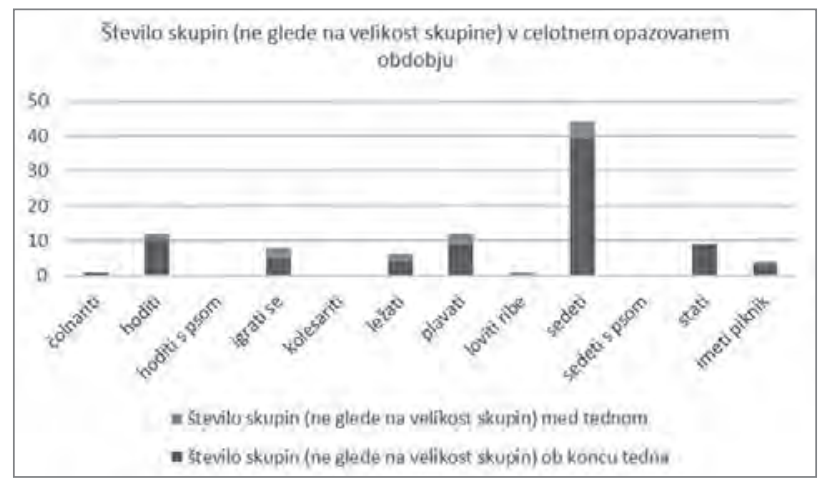

Slika 5: Število skupin (ne glede na velikost skupine) v celotnem opazovanem obdobju (izdelala: Barbara Goličnik Marušić)

sobnosti prostora za zasedbo s prostočasnimi dejavnostmi so bili pomembni še izvedeni podatki, na primer opredelitev vrste dejavnosti (dejanske in razvrščene v skupine: aktivne, pasivne, v prehodu čez prostor), načini zapolnjevanja prostora ter pogostost (pogosto, občasno, redko izvedene) in intenziteta dejavnosti (število prisotnih, vključenih $\mathrm{v}$ isto dejavnost). Izsledki teh analiz so navedeni v treh podpoglavjih.

\subsection{Osnovne opisne analize}

Največji obisk Jezera pri Podpeči je bil evidentiran v nedeljo, 17. 6. 2018, ko sta bila opazovanje in kartiranje vedenj opravljena popoldne $(14.00-19.00)$ in v nedeljo, 19. 8. 2018, ko sta opazovanje in kartiranje vedenj potekala dopoldne $(10.00-14.00)$. V obeh primerih je bilo v opazovanem obdobju na območju opazovanja približno 300 ljudi. Komentarji so za izbrane dni podani primerjalno z drugimi dnevi ali glede na intenziteto in značilnost obiska ob koncih tedna.

Kumulativni vedenjski zemljevid zasedbe prostora $\mathrm{v}$ vseh opazovalnih dneh prikaže lokacije uporabe prostora tako za posameznike (točkaste oznake) kot za skupine (poenostavitev prikaza z različno velikimi krogi). Kumulativni vedenjski zemljevid pokaže zasedbo prostora in prostorsko razporeditev rab $\mathrm{v}$ vseh opazovalnih dneh, na njegovi podlagi je razvidna obremenitev prostora glede na gostoto in intenziteto razmeščanja rab v prostoru. Nazorno pokaže, kateri deli prostora so bolj in kateri manj v rabi, in je izhodišče za nadaljnje analize o dejanskih rabah, njihovih intenzitetah, pogostosti, združljivosti ipd.

Podrobna analiza dejavnosti na Jezeru pri Podpeči je pokazala, da največ obiskovalcev tako ob koncu tedna kot med tednom poseda na zatravljenem robu jezera, da se ob koncu tedna poleg posedanja najpogosteje poležava na travi, med tednom pa so najpogostejši sprehodi. Podobno potrjuje analiza zasedbe prostora, kadar ne gre za posameznike ali pare, temveč se v prostoru pojavijo skupine (tri osebe ali več skupaj). Največ skupin je bilo opaženih pri posedanju, plavanju in hoji ali sprehodu. Primerjava med uporabo prostora ob koncih tedna in med tednom pokaže, da je pri vodnih dejavnostih ob koncu tedna izrazitejše plavanje, med tednom pa ribolov.

Poleg ugotavljanja kumulativnih učinkov obremenitev prostora je pomembno tudi prepoznavanje načina zapolnjevanja prostora. Značilnosti dnevnega zapolnjevanja prostora potrjuje prikaz zasedbe prostora v dneh, ko obiskovalcev ni veliko, saj je mogoče sklepati na značilnosti sekvenčne zasedbe prostora. Primerjava na sliki 6 ponazarja dni, ko je bil obisk velik (a -b), in dan, ko je bilo obiskovalcev veliko (c). Značilnosti in členitev prostora vplivajo na to, da so najprej zasedeni prostori ob pomolih in tisti, kjer je na voljo senca, potem se počasi polni prostor med pomoloma. Zasedba prostora na sliki c pokaže, da ko se prostor med pomoloma tako zapolni, da se uporabniki še ne počutijo neugodno, se postopoma polni zahodni rob jezera in nato še južni del (pretežno s kratkotrajnimi dejavnostmi).

Iz analiz je razvidno, da je Jezero pri Podpeči priljubljena točka obiskovalcev vseh starostnih skupin. Mladostniki prihajajo pretežno v večjih skupinah, njihovo druženje ostaja skupinska dejavnost tako na obali kot v vodi. Manjše skupine so druži- 


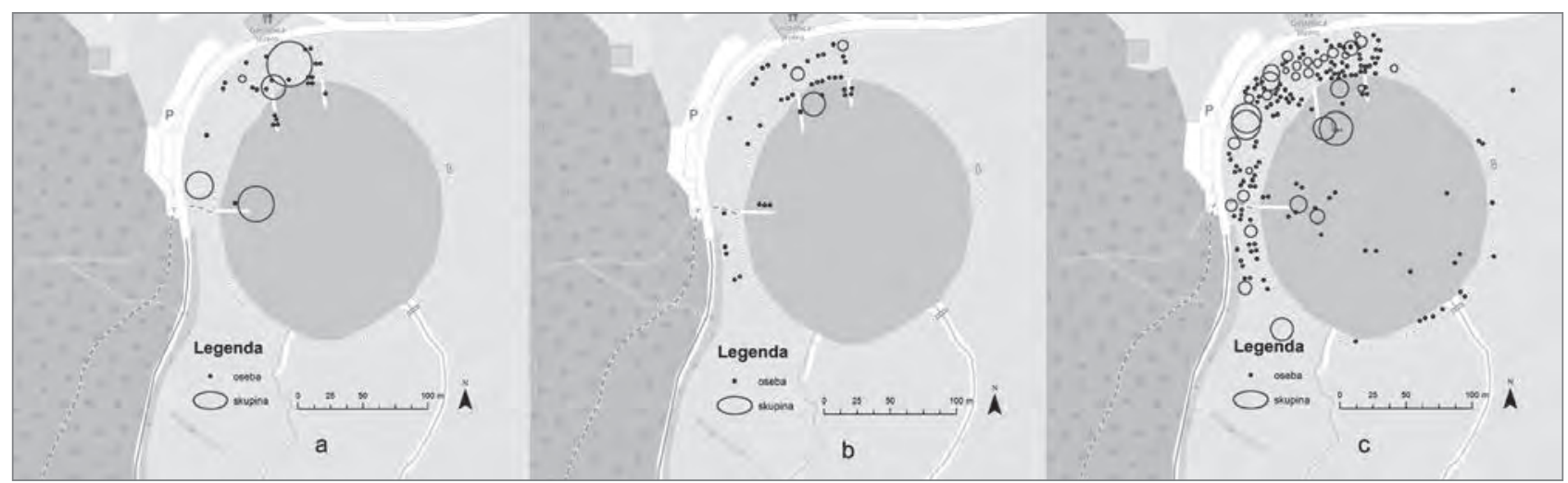

Slika 6: Način zapolnjevanja prostora, prikazan na podlagi uporabe prostora v treh dneh: 15. 6. (a), 26. 6. (b) in 17. 6. 2018 (c) (izdelala: Nevenka Mihevc, vir: OpenStreetMap, terenski zajem podatkov)

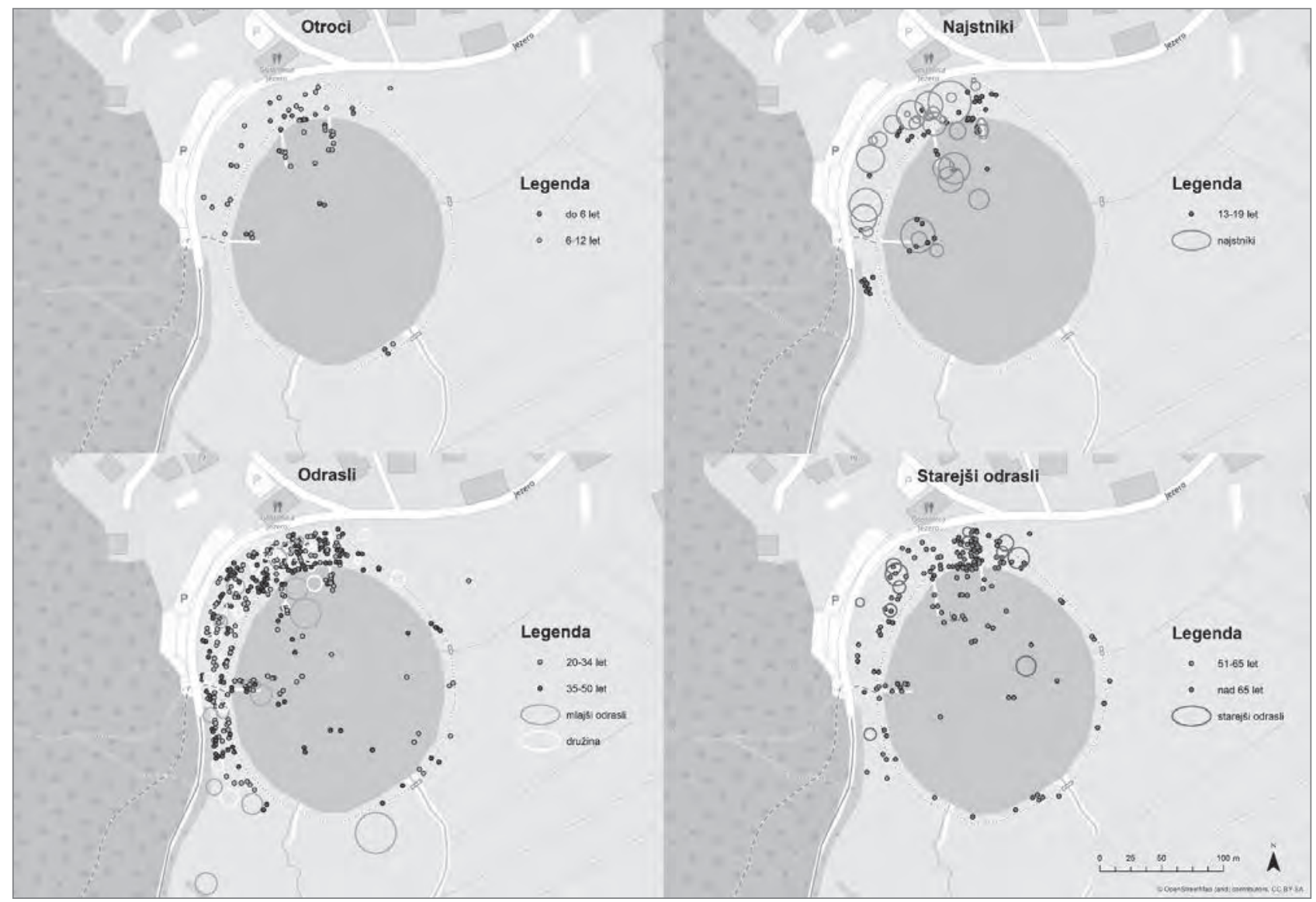

Slika 7: Zasedba prostora glede na starost (izdelala: Nevenka Mihevc, vir: OpenStreetMap, terenski zajem podatkov)

ne. Iz dodatne analize je razvidno, da se otroci, mlajši od šest let, navadno ne oddaljujejo od jedra, kjer je družina, in so v spremstvu odraslih. V manjših skupinah pogosto prihajajo mlajši odrasli (20 -34 let) in družine. Starejši odrasli (51 -65 let) prihajajo tudi v večjih skupinah. Zanimivo, iz analiz je razvidno, da ti na jezero pridejo intenzivno plavat. Starostniki, starejši od 65 let, so navadno sprehajalci.

Iz analize tipičnega dneva uporabe prostora jezera izhaja, da se družine in starejši odrasli zadržujejo pretežno na severni obali, $\mathrm{v}$ senci. Mlajši odrasli so posamično ali v skupinah enakomer- no razporejeni od senčnega območja do južnega dela zahodne obale jezera, za plavanje pa so najpogumnejši starejši odrasli. Rob z naravno zarastjo je v rabi za sprehod okoli jezera, za druge dejavnosti, pri katerih se posamezniki dlje zadržujejo na tem območju, pa se ne uporablja.

\subsection{Vrsta dejavnosti}

$\mathrm{Na}$ podlagi zbranih podatkov so sledile analize izvedenih podatkov. Prilagojeno po Goličnik (2007) so bile dejavnosti razvrščene $\mathrm{v}$ tri skupine: dejavne $\mathrm{v}$ prostoru (tj. biti aktiven 


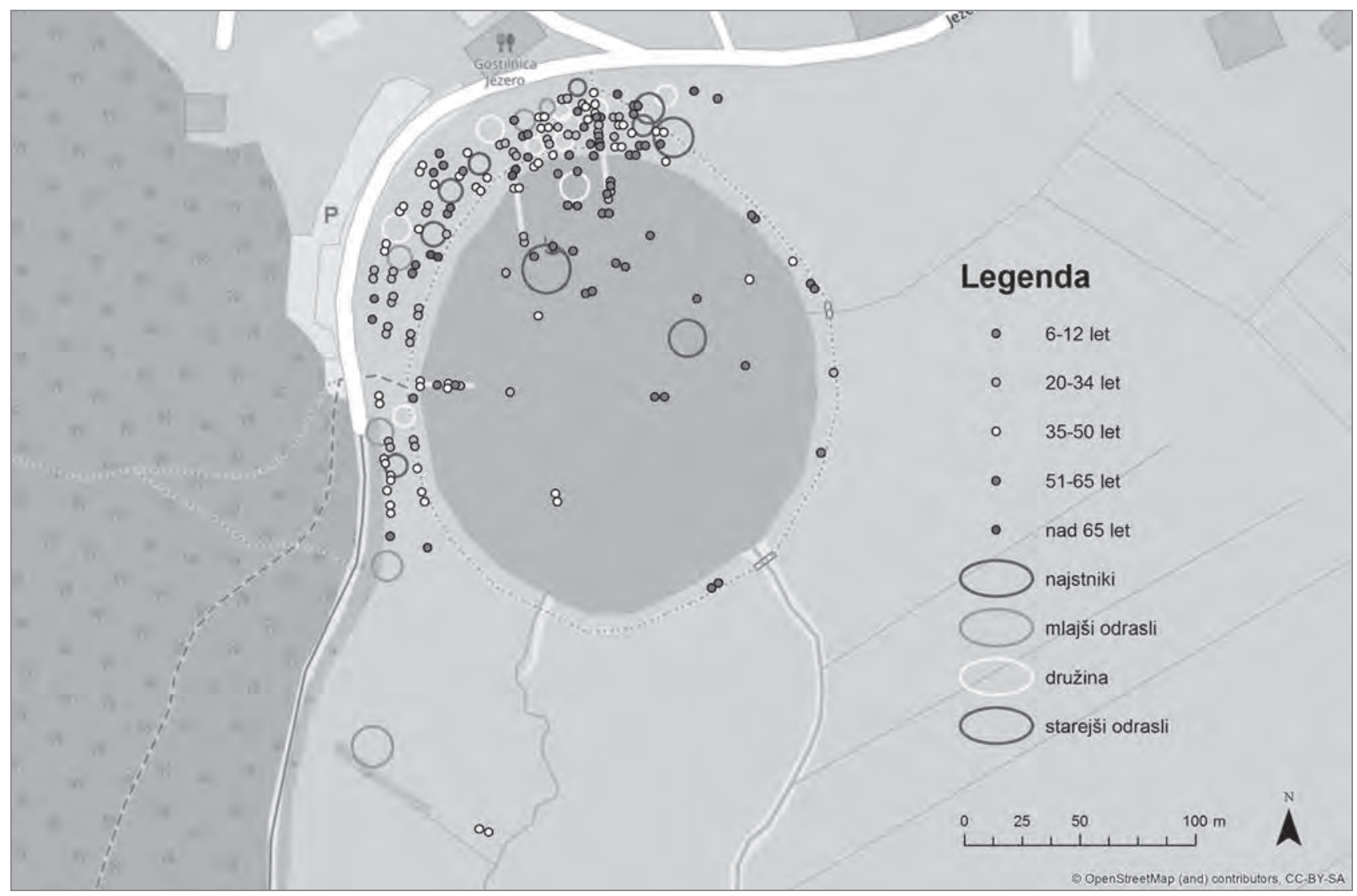

Slika 8: Primer zasedbe prostora za enega tipičnih dni, 19. 8. 2018 (izdelala: Nevenka Mihevc, vir: OpenStreetMap, terenski zajem podatkov)

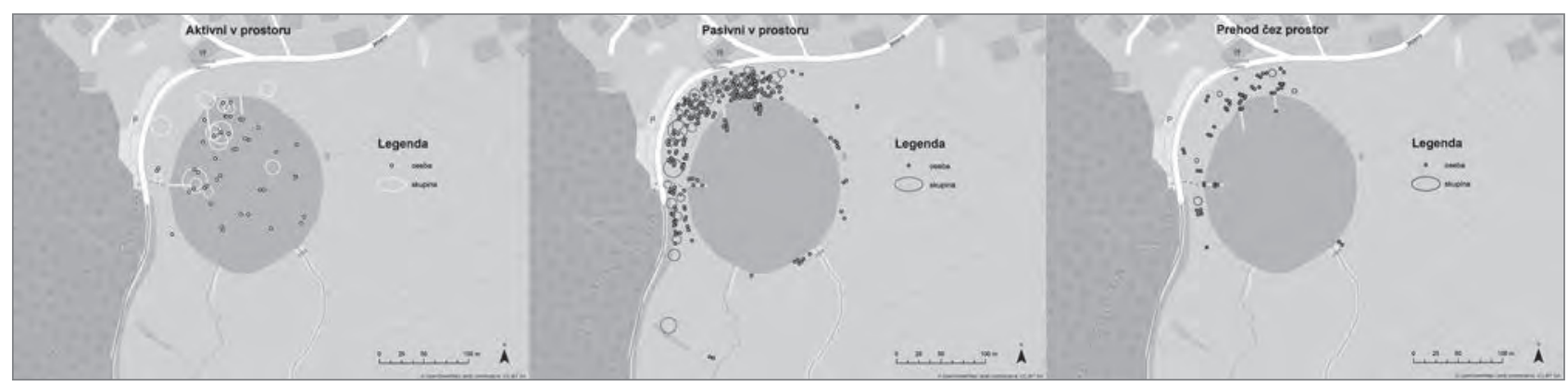

Slika 9: Primeri kumulativne zasedbe prostora glede na vrsto dejavnosti v primeru pogosto obiskanih dni (15. 6., 17. 6. in 19. 8. 2018) (izdelala: Nevenka Mihevc, vir: OpenStreetMap, terenski zajem podatkov)

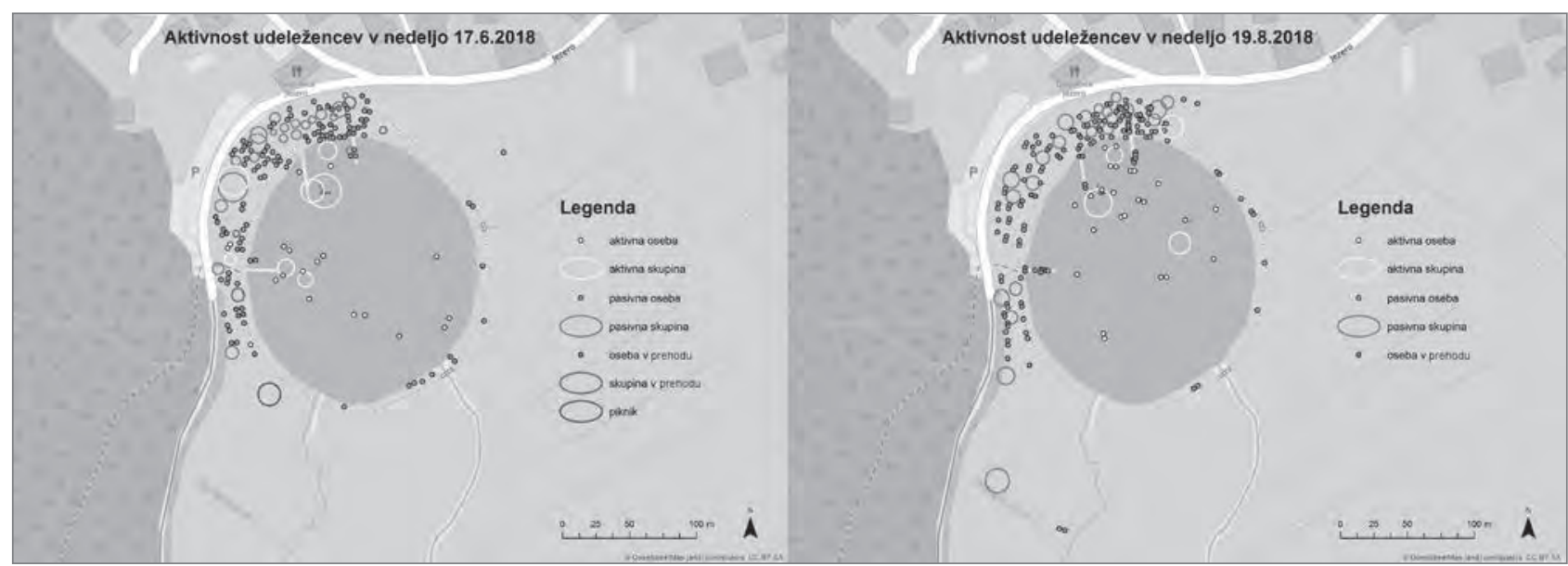

Slika 10: Dnevni vedenjski vzorci zasedbe prostora glede na dejavnost udeležbe v nedeljo popoldne (17. 6. 2018) in nedeljo dopoldne (19. 8. 2018) (izdelala: Nevenka Mihevc, vir: OpenStreetMap, terenski zajem podatkov) 


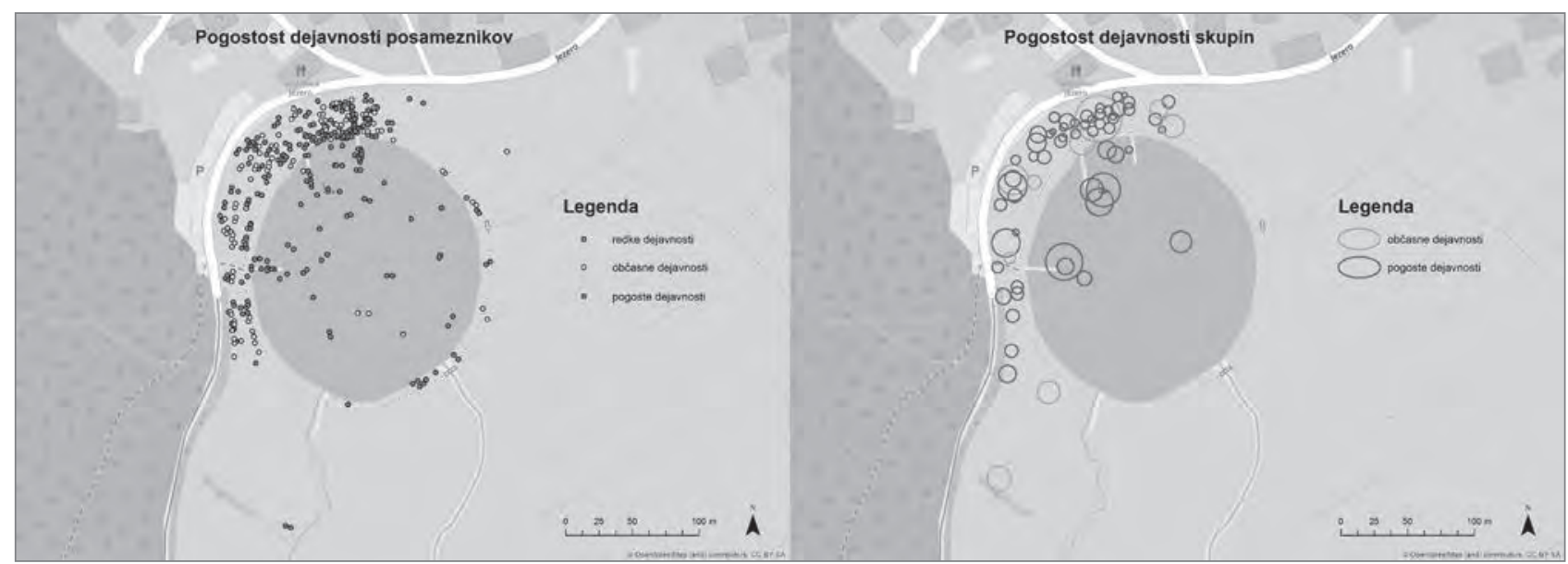

Slika 11: Pogostost pojavljanja uporabnikov ob podpeškem jezeru: a. posamezniki, b. skupine (izdelala: Nevenka Mihevc, vir: OpenStreetMap, terenski zajem podatkov)

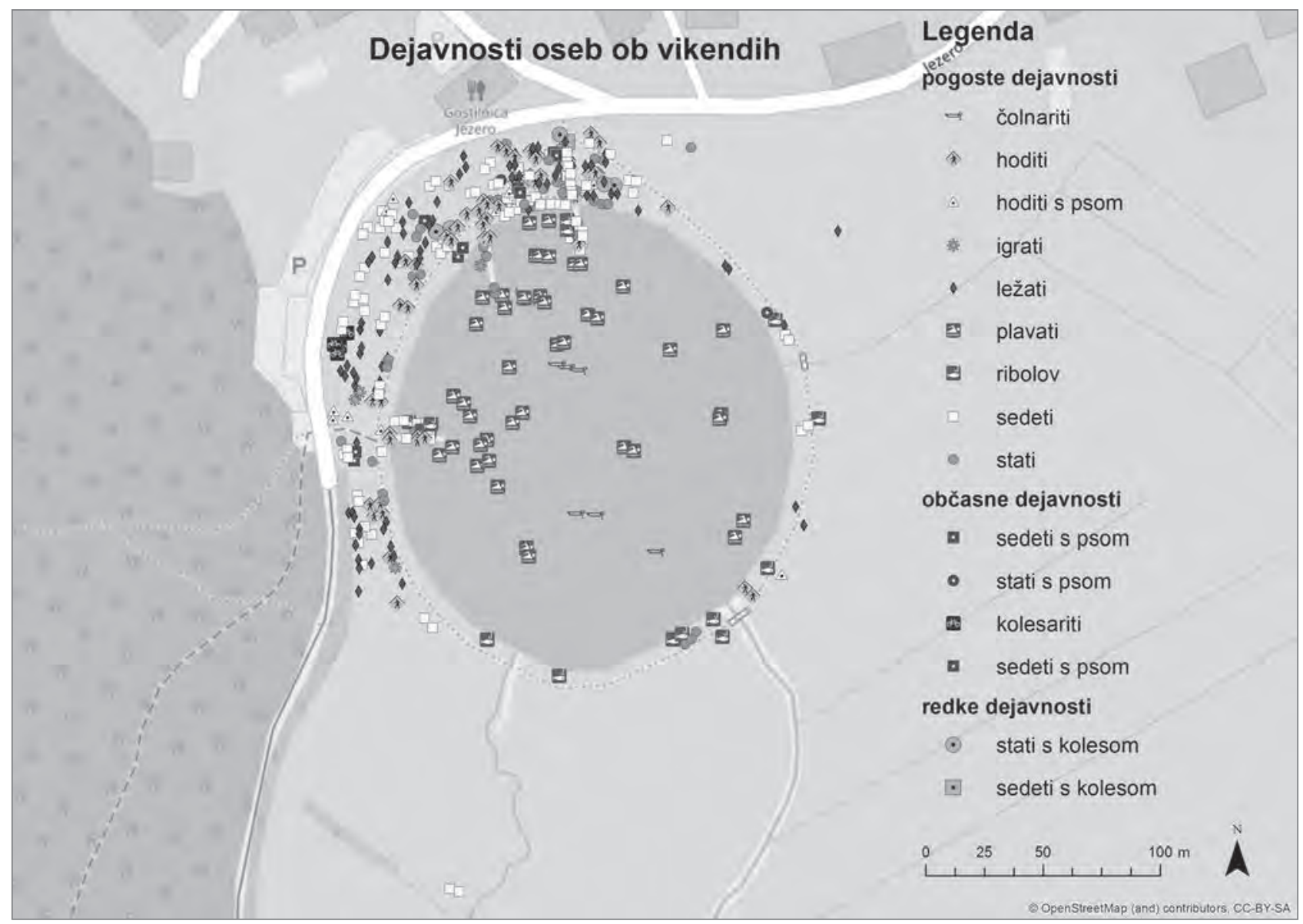

Slika 12: Vrste dejavnosti glede na pogostost pojavljanja ob koncu tedna (izdelala: Nevenka Mihevc, vir: OpenStreetMap, terenski zajem podatkov)

$\mathrm{v}$ prostoru, na primer žogati se), pasivne v prostoru ( $\mathrm{tj}$. biti pasiven $\mathrm{v}$ prostoru, na primer ležati ali sedeti $\mathrm{v}$ travi) in tiste $\mathrm{v}$ prehodu čez prostor (tj. biti v prehodu čez prostor, na primer teči ali sprehajati se). Iz analiz je razvidno, da je dejavno preživljanje časa ob podpeškem jezeru $\mathrm{v}$ glavnem vezano na vodno okolje: plavanje in igre $\mathrm{v}$ vodi. Na bregu so v skupini aktivnih v ves čas izvajanih dejavnostih izpostavljene nekatere skupine, ki so imele piknik, pri čemer so se prisotni vključevali v aktivne igre z žogo ali lovljenje (otroci). Za ponazoritev podajamo prikaz dnevnih vedenjskih vzorcev zasedbe prostora glede na dejavnost udeležbe v nedeljo, 17.6. 2018, popoldne in nedeljo, 19. 8. 2018, dopoldne. 


\subsection{Pogostost izvajanja dejavnosti in intenziteta pritiska na prostor}

Nadaljnje analize so bile osredotočene na pogostost izvajanja neke dejavnosti in na presojo intenzitete pritiska na prostor. Pogosto izvedene dejavnosti so tiste, ki so bile opažene v več kot $66 \%$ opazovalnih dni, občasno izvedene so tiste, ki so se pojavile v $33-66 \%$ opazovanj, in redko izvedene pa so tiste, ki so bile opažene v manj kot 33 \% opazovanj. Iz analize je razvidno, da se pogosto izvajajo dejavnosti v vodi in med severnima pomoloma, ob zahodnem pomolu in na položni brežini zahodnega roba jezera. To območje je tako skoraj vedno v rabi, aktualno tako za pasivne kot aktivne dejavnosti. Na zemljevidu, ki prikazuje posameznike, je razvidno, da sta posedanje in ležanje na travi pogostejša bliže vodnemu robu (brežine med pomoli).

Iz osnovne analize zemljevidov je razvidno, kateri deli prostora so navadno zasedeni s pogosto izvedenimi dejavnostmi in kateri z redko izvedenimi, kar posledično kaže na to, za katere mikrolokacije lahko pričakujemo, da bodo bolj obremenjene od drugih. Primerjava zemljevidov pokaže še, da so ob dnevih, ko je obisk velik, navadno pojavljajo običajne, vedno pričakovane ali pogosto izvedene dejavnosti in da se ob dnevih, ko takšnega navala ni, pojavljajo tudi druge dejavnosti. Analiza pogostosti pojavljanja dejavnosti je pomembna zato, ker razkriva, da so $\mathrm{v}$ prostoru ne le pričakovane in običajne dejavnosti (tj. tiste, ki jih pričakujemo, ker se navadno pogosto izvajajo), ampak so lahko tudi dejavnosti, ki jih manj pričakujemo in jih nekdo izvaja. Analize lahko razkrijejo, katere dejavnosti so takšne in v kakšni relaciji so glede na pogoste dejavnosti. Še posebej je to pomembno pri primerjavah pojavljanj dejavnosti med tednom in ob koncu tedna, saj se pokaže, da je občasno ali redko izvedene dejavnosti bolj verjetno mogoče zaznati med tednom in da bolj verjetno zajemajo vključevanje lokalnega prebivalstva, in ne izletnikov ali obiskovalcev od daleč.

V tem kontekstu je podrobna analiza opazovalnih dni pokazala, da Jezero pri Podpeči ni nujno končna kolesarska destinacija, da pa se občasno rekreativni kolesarji tam ustavijo in nato nadaljujejo pot: med tednom so bili kolesarji opaženi redko, ob koncu tedna pa občasno. Analize so pokazale, da je Jezero pri Podpeči izrazita destinacija zadrževanja, tj. za dejavnosti, ki so bile opažene pogosto, je značilno, da se ves čas izvajajo v prostoru, in to kot pasivne, npr. sedenje / posedanje, ali aktivne, npr. plavanje. Posebna primerjava pogostosti izvajanja dejavnosti le glede na dejavnosti, ki so bile opažene ob koncu tedna, pokaže, da se tedaj značilno pojavljajo enake vrste dejavnosti, zato so mnoge pogoste.

\section{Rezultati}

$\mathrm{V}$ tem poglavju na podlagi predstavljenih analiz interpretiramo rezultate tako, da bi zasnovali koncept nosilne sposobnosti zavarovanih krajin za zasedbo in opredelili koncept zelene infrastrukture z vidika kulturnih ekosistemskih storitev, ki upoštevajo ranljivost naravnega prostora.

\subsection{Nosilna sposobnost območja za rekreacijo}

Na podlagi predstavljenih analiz smo opredelili splošno stopnjo presoje nosilne sposobnosti vrednega krajinskega območja za rekreacijo. Empirični rezultati so pokazali, da je na območju intenzivne rabe $\mathrm{z}$ dlje časa pogosto izvajanimi aktivnimi ali pasivnimi dejavnostmi mogoče ugotoviti, da ob dani obremenitvi povprečna površina kopnega dela na uporabnika znaša najmanj $30 \mathrm{~m}^{2}$ ali, posplošeno, če bi se uporabniki enakomerno razporedili, bi na vsakega pripadlo območje kroga s polmerom vsaj $3 \mathrm{~m}$. Podatki so pokazali, da se ob najbolj obiskanih dnevih dnevno na območju podpeškega jezera zadržuje približno 300 ljudi, ki so na območju prisotni vsaj nekaj ur. Območje, ki ga pri tem zasedejo (OZ), meri od 3.500 (upoštevano območje gostejše zasedbe) do $8.000 \mathrm{~m}^{2}$ (območje z upoštevano robno razpršenostjo rab). Izračunani za dve območji se razlikujeta glede na porazdelitev uporabnikov na prostoru. Večje območje vključuje vse lokacije, ki so bile uporabljene kadar koli $\mathrm{v}$ celotnem opazovalnem obdobju (tj. najbolj razpršen vzorec kumulativne rabe prostora), območje gostejše uporabe pa se nanaša na območje, ki ga običajno zasedajo uporabniki, pri čemer so izključene prav tiste lokacije, ki se občasno ali zelo redko izberejo za uporabo, npr. sedenje ali ribolov (glej sliko 13).

Ocene so pokazale, da pri tem na posameznika pripada območje kroga $(\mathrm{O})$ s polmerom $2-3 \mathrm{~m}$.

$C=\frac{A U}{N U} ; C=\pi r^{2}$,

pri čemer je:

$A U$ : celotno območje zasedbe,

$N U$ : število ljudi na celotnem območju zasedbe,

$C$ : posplošena vrednost površine območja na posameznika, $r$ : polmer površine posplošene vrednosti območja na posameznika.

$$
\begin{aligned}
& C 1=\frac{3.500 \mathrm{~m}^{2}}{300}=12 \mathrm{~m}^{2}, C 1=12 \mathrm{~m}^{2}=\pi r^{2}, r=\sqrt{\frac{01}{\pi}}, r=\sqrt{3,8} \sim 1,9 \mathrm{~m} \\
& C 2=\frac{0.000 \mathrm{~m}^{2}}{300}=26 \mathrm{~m}^{2}, C 2=26 \mathrm{~m}^{2}=\pi r^{2}, r=\sqrt{\frac{02}{\pi}}, r=\sqrt{8,2}-2,8 \mathrm{~m}
\end{aligned}
$$




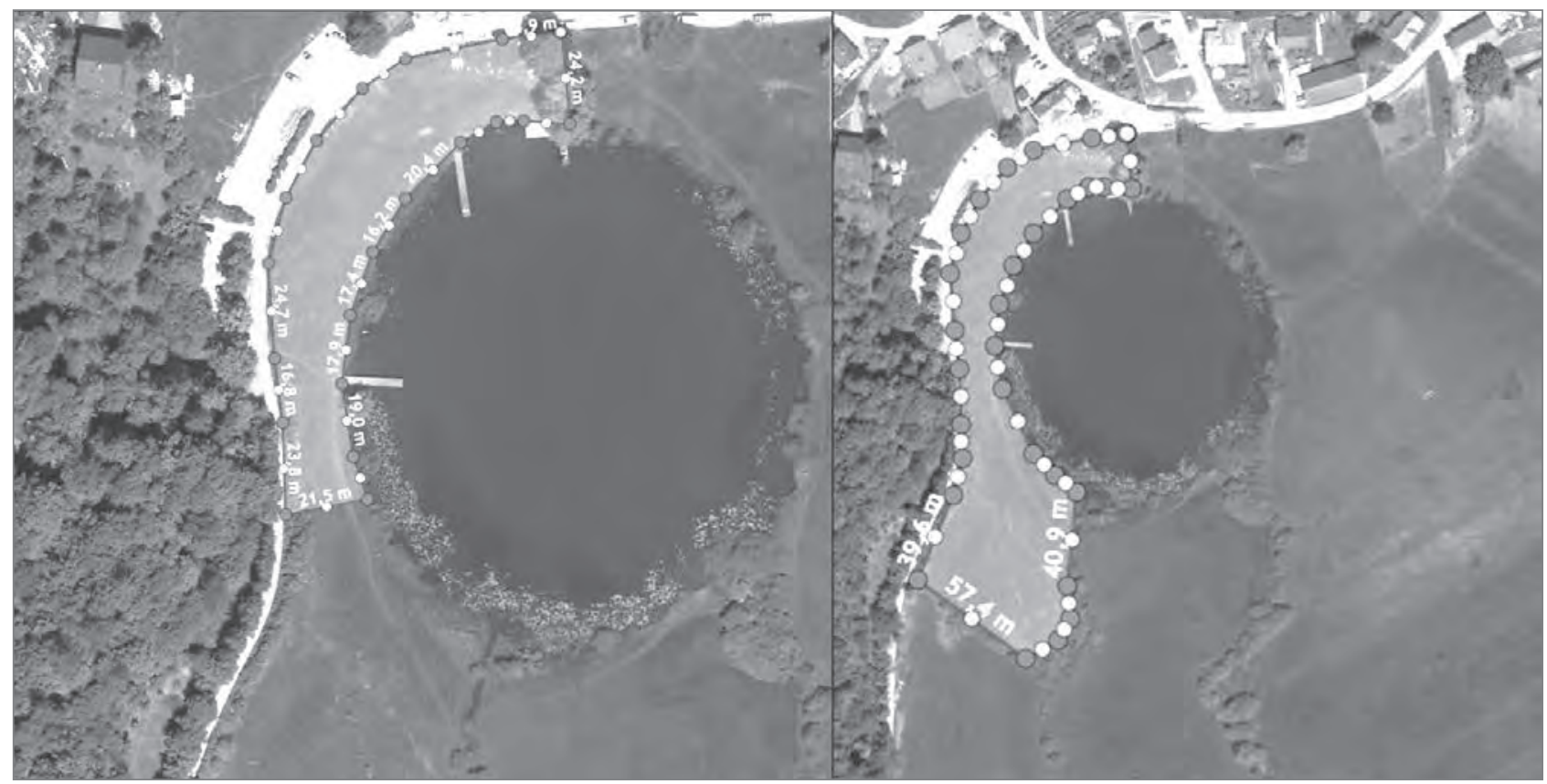

Slika 13: Ilustracija dveh območij, izbranih za izračun nosilne sposobnosti prostora (ilustracija: Nevenka Mihevc, vir: Agencija Republike Slovenije za okolje, Atlas kakovosti okolja)

\subsection{Razprava}

Pri trenutni razvojni stopnji koncepta nosilne sposobnosti območja za uporabo gre za okvirne ocene, a pomembno je, da se tovrstne teme začnejo obravnavati, da se oblikujejo predstave o dejanskih rabah in njihovih učinkih na prostor ter sposobnostih prostora za naravno regeneracijo. Za ponazoritev, za ustrezno presojo nosilne sposobnosti prostora za zasedbo $\mathrm{z}$ rabami za prosti čas, rekreacijo in sprostitev je poleg pogostosti pojavljanja posamezne dejavnosti pomembno tudi, kako intenzivna je, tj. koliko ljudi je hkrati vključenih v enako vrsto dejavnosti na območju opazovanja. Dejavnosti, ki so bile praviloma opažene v večjem številu ob koncu tedna, so sedeti ali posedati, ležati na travi in plavati. Navadno pogoste, vendar ne zelo intenzivne (malo ljudi) dejavnosti so bile ribolov, opazovanje ali postopanje ter hoja ali sprehod.

Zato so takšne presoje kljub vsemu lahko dober temelj za začetna izhodišča in iskanje odgovorov (ali novih vprašanj). Izračuni, kot je ponazorjeno zgoraj, so temelj za nadaljnje razmišljanje in snovanje akcijskih načrtov ali ukrepov za usmerjanje rekreativne in sprostitvene dejavnosti na območje. Pomagajo tudi ugotoviti, kako lahko pri novih lokacijah, na katere želimo usmeriti tovrstno rabo, predvidimo zmogljivosti in usmerimo dejavnosti nanje. Še več, pripomorejo lahko tudi k zasnovi prerazporejanja in usmerjanja rekreativcev na sorodna območja ali doprinesejo $\mathrm{k}$ vzdržnemu upravljanju zavarovanih območij z vidika rekreacije in obiska. Na podlagi takih rezultatov je mogoče sklepati, pri kakšni obremenitvi se hkrati zagotavlja tudi ustrezna zasebnost $\mathrm{v}$ javnem prostoru (Hall, 1966). Na primer abstraktni vplivni prostor (površina posplošene vrednosti območja na posameznika s polmerom $2-3 \mathrm{~m}$ ), ki v okviru tega pilotnega primera pripada posamezniku, po okvirni oceni ustreza antropološkim dimenzijam (Hall, 1966) oddaljene družbene distance, ki po Hallu (1966) pomeni razdaljo med 2,1 in 3,7 metra.

Te prve ocene so predhodno izhodišče za nadaljnje raziskovanje potenciala koncepta nosilne sposobnosti prostora za zasedbo, ne le z vidika družbenih dimenzij prostora, temveč tudi z vidika naravovarstva in biotske raznovrstnosti. Rezultati pilotne študije so pokazali, da je južni del jezera zaradi svojih naravnih značilnosti manj privlačen za posedanje ali ležanje na travi. Zaraščenost, vodnatost, pomanjkanje sence in uhojene poti so le nekatere značilnosti, zaradi katerih se obiskovalci tam ne zadržujejo dlje. Omenjeni del opravlja pomembno ekosistemsko funkcijo in funkcijo biotske raznovrstnosti, zato je $s$ tega vidika smiselno poudariti, da je za nosilno zmogljivost širšega območja jezera smiselno ljudi še naprej zadrževati na enem koncu, da lahko ta južni del opravlja svojo naravno funkcijo in da v primeru pritiskov na prostor rešitve, ki bi iskale urejanje prostora za rabo na južnem delu, ne bi bile primerne.

\section{Sklep}

$\mathrm{Na}$ podlagi uveljavljene metode opazovanj in vedenjskih zemljevidov je članek osvetlil spoznanja o osnovnih značilnostih uporab prostora ob Jezeru pri Podpeči in podal komentarje glede na značilnosti razporeditev dejavnosti po prostoru z 
vidika številnih parametrov: gostote zasedbe in načina polnjenja prostora, vrste in intenzitete dejavnosti, prisotnost uporabnikov glede na starostne skupine ipd. Kot glavni rezultat je uvedel koncept nosilne sposobnosti prostora za zasedbo kot novo količino za ugotavljanje preobremenjenosti prostora $\mathrm{z}$ rabo. Ob najrazličnejših pritiskih družbe na prostor je tudi z vidika (u)porabe prostora pomembno prepoznati priložnosti in omejitve prostorov, še posebej takšnih, ki so prepoznani kot vredne naravne ali kulturne krajine, saj so kot taki še toliko bolj privlačni za (upo)rabo. Na podlagi pilotnih preveritvev je bil postavljen osnutek koncepta in izvedene so bile prve empirične meritve. Prve ocene nosilne sposobnosti prostora na podlagi posplošene površine območja na posameznika pomenijo le začetek. Več ko bo v prihodnje opravljenih podobnih opazovanj in analiz po predlaganem protokolu, $\mathrm{z}$ večjo gotovostjo bomo lahko dobili izboljšane mere stopenj nosilnih sposobnosti prostora za zasedbo. Treba bo večplastno obravnavati odnos med uporabo prostora, njegovo pojavnostjo in ekosistemskimi značilnostmi.

Barbara Goličnik Marušić

Urbanistični inštitut Republike Slovenije, Ljubljana, Slovenija

E-naslov: barbara.golicnik-marusic@uirs.si

Nevenka Mihevc

Zavod Republike Slovenije za varstvo narave, Ljubljana, Slovenija

E-naslov: nevenka.mihevc@gmail.com

Manca Dremel

Univerza v Ljubljani, Biotehniška fakulteta, Oddelek za biologijo,

Ljubljana, Slovenija

E-naslov: manca.dremel@gmail.com

\section{Zahvala}

Raziskava se je izvajala v okviru projekta LOS_DAMA! - Razvoj krajine in odprtega prostora na alpskih metropolitanskih območjih, ki je bil odobren na drugem razpisu programa transnacionalnega teritorialnega sodelovanja Območje Alp 2014 -2020 in raziskovalnega programa P5-0100 Prostorsko načrtovanje, ki ga sofinancira Javna agencija za raziskovalno dejavnost Republike Slovenije iz državnega proračuna. Nekatera izhodišča izhajajo tudi iz projekta J5-7178 Integralni sistem poplavno vzdržnega prostorskega načrtovanja, ki ga sofinancira Javna agencija za raziskovalno dejavnost Republike Slovenije iz državnega proračuna, poleg tega so rezultati iz objavljenega članka uporabni za nadaljnjo gradnjo t. i. uporabniškega modula sistema poplavno vzdržnega prostorskega načrtovanja, razvitega v zadnjeomenjenem projektu.-

\section{Viri in literatura}

ARSO (2019): Agencija Republike Slovenije za okolje, Atlas okolja. Dostopno na: http://gis.arso.gov.si/atlasokolja/ profile.aspx?id=Atlas_Okolja_AXL@Arso (sneto 13.6. 2019).

Chang, Q., Li, X., Huang, X. in Wu, J. (2011): A GIS-based green infrastructure planning for sustainable urban land use and spatial development.
Procedia Environmental Sciences, 12(2012), str. 491-498. DOI: 10.1016/j.proenv.2012.01.308

Evropska komisija (2013): Communication from the commission to the European Parliament, the Council, the European Economic and Social Committee and the Committee of the Regions: Green Infrastructure (GI) - Enhancing Europe's Natural Capital. Dostopno na: http: eur-lex.europa.eu/resource.html?uri=cellar:d41348f2-01 d5-4abe-b8174c73e6f1b2df.0014.03/DOC_1\&format=PDF (sneto 12. 2. 2018).

Evropska komisija (2016): Supporting the implementation of green infrastructure. Directorate-General for the Environment, ENV.B.2/ SER/2014/0012. Dostopno na: http: https://ec.europa.eu/environment/ nature/ecosystems/docs/green_infrastructures/GI\%20Final\%20Report. pdf (sneto 25. 4. 2018).

Evropska komisija (2018): Mapping and assessment of ecosystems and their services: An analytical framework for mapping and assessment of ecosystem condition in EU. Luxembourg: Publications Office of the European Union.

Gill, S. E., Handley, J. F., Ennos, A. R., in Pauleit, S. (2007): Adapting cities for climate change: The role of green infrastructure. Built Environment, 33(1), str. 115-133. DOI: 10.2148/benv.33.1.115

Goličnik, B. (2006): Vedenjski zemljevidi ljubljanskih trgov in parkov: novi izzivi in pogledi na načrtovanje in urejanje prostora (= Urbani izziv: publikacije). Ljubljana, Urbanistični inštitut Republike Slovenije.

Goličnik, B., in Ward Thompson, C. (2002): Opazovanje in vedenjski zemljevidi: metoda raziskovanja javnega odprtega prostora $v$ mestu. Urbani izziv, 13(1), str. 82-89. DOI: 10.5379/urbani-izziv-2002-13-01-011

Goličnik Marušić, B. (2015): Social behaviour as a basis for design and development of green infrastructure. Urbani izziv, 26, str. 130-149. DOI: 10.5379/urbani-izziv-en-2015-26-supplement-009

Goličnik Marušić, B., in Praper Gulič, S. (2018): Razvoj uporabniškega modula: prispevek k poplavno vzdržnemu prostorskemu načrtovanju. Urbani izziv, 19(2), str. 111-125.

DOI: 10.5379/urbani-izziv-2018-29-02-004

Hall, E. T. (1966): The hidden dimension. New York, Bantam Doubleday Dell Publishing Group.

LOS DAMA! (2018): Green infrastructure for better living. Dostopno na: https://www.alpine-space.eu/projects/los_dama/en/ home (sneto 30. 5. 2019).

Meerow, S. in Newell, J. P. (2017): Spatial planning for multifunctional green infrastructure: Growing resilience in Detroit. Landscape and Urban Planning, 159, str. 62-75. DOI: 10.1016/j.landurbplan.2016.10.005

Openstreetmap Foundation (2018): Openstreetmap. Dostopno na: https://www.openstreetmap.org (sneto 12. 5. 2018).

Raymond, C. M., Berry, P., Breil, M., Nita, M. R., Kabisch, N., in de Bel, M. (2017): An impact evaluation framework to support planning and evaluation of nature-based solutions projects. Report prepared by the EKLIPSE Expert Working Group on Nature-Based Solutions to Promote Climate Resilience in Urban Areas. Wallingford, UK, Centre for Ecology \& Hydrology.

Taylor, L., in Hochuli, D. F. (2017): Defining greenspace: Multiple uses across multiple disciplines. Landscape and Urban Planning, 158, str. 2538. DOI: 10.1016/j.landurbplan.2016.09.024

Tzoulas, K., Korpela, K., Venn, S., Yli-Pelkonen, V., Ka'zmierczak, A., Niemela, J., in James, P. (2007): Promoting ecosystem and human health in urban areas using green infrastructure: A literature review. Landscape and Urban Planning, 81, str. 167-178.

DOI: 10.1016/j.landurbplan.2007.02.001

Ward Thompson, C. (2013): Activity, exercise and the planning and design of outdoor spaces. Journal of Environmental Psychology, 34, str. 79-96. DOI: 10.1016/j.jenvp.2013.01.003 